\title{
Parastomal Hernia Prevention With Mesh in the Context of Laparoscopic Approach: An Opinion Based on Current Literature
}

\author{
Manuel López-Cano ${ }^{1 *}$ and José Antonio Pereira Rodriguez ${ }^{2}$ \\ ${ }^{1}$ Department of General Surgery, Abdominal Wall Surgery Unit and General and Digestive Surgery Research Group, Institut \\ de Reserca Vall d'Hebron (VHIR), Hospital Universitari Vall d'Hebron, Universitat Autònoma de Barcelona, Barcelona, Spain, \\ ${ }^{2}$ Servei de Cirurgia General, Hospital del Mar, Parc de Salut Mar, Departament de Ciències Experimentals i de la Salut, \\ Universitat Pompeu Fabra, Barcelona, Spain
}

Keywords: laparoscopy, parastomal, hernia, prevention, mesh

OPEN ACCESS

Edited by:

Gabriel Sandblom,

Karolinska Institute (KI), Sweden

Reviewed by:

Sanoop Koshy Zachariah, Malankara Orthodox Syrian Church Medical College Hospital, India Noushif M

Aster Medcity, India

*Correspondence:

Manuel López-Cano 27689m/c@comb.cat; mlpezcano@gmail.com

Specialty section: This article was submitted to Visceral Surgery,

a section of the journal

Frontiers in Surgery

Received: 06 November 2017 Accepted: 13 February 2018 Published: 06 March 2018

Citation: López-Cano M and Pereira Rodriguez JA

(2018) Parastomal Hernia Prevention With Mesh in the Context of Laparoscopic Approach: An Opinion Based on Current Literature.

Front. Surg. 5:19.

doi: 10.3389/fsurg.2018.00019

\section{INTRODUCTION}

Since the 1990s, laparoscopic surgery (LS) has been a true revolution in the field of surgery. LS decreases the lesions inherent in surgical access modalities, reducing operative morbidity and reaching similar or even better results than those related to open surgery (OS) (1). Nowadays, surgical specialties related to stoma formation (i.e., general surgery and urology) routinely incorporate LS as a surgical approach modality. However, despite this minimal access approach, the incidence of a parastomal hernia $(\mathrm{PH})$ remains high and can vary depending on the type of stoma. In this way, the frequency of $\mathrm{PH}$ associated with an end-colostomy ranges from 4 to $93 \%$. This disparity can be explained by the diagnostic method used. Thus, when the diagnosis is clinical, the values range from 4 to $48 \%$ (2), and when it is radiological, from 78 to $93 \%(3,4)$. PH figures associated with an end-ileostomy between 2 and $28 \%$ have been described (5) and when associated with an ileal conduit diversion can be up to $29 \%$ (6). The lack of a uniform PH definition (clinical or radiological) may explain the difficulty of quantifying the exact incidence of this pathology. Independently of the surgical approach (open or laparoscopy) $\mathrm{PH}$ repair is notoriously difficult (7) and surgical research has started to focus more and more on the prevention of $\mathrm{PH}$ formation by using mesh at the time of stoma construction in the context of both open and laparoscopic approaches (8).

Interestingly, in parallel with LS and in response to limitations in the understanding and use of published evidence, evidence-based medicine (EBM) began as a movement in the early 1990s and integrates clinical judgment, recommendations from the best available evidence and the patient's values (9). Knowledge of the "best available evidence" necessarily requires an understanding of study design hierarchy. The reason for which studies are placed into a hierarchy is that those at the top are considered the "best evidence", which allows the establishment of a recommendation for practice (10). In general, there are different systems to rate the quality of evidence (high-quality evidence rated as "1" or "high" and low-quality evidence rated as "4 or 5" or "low") (11). It is not the aim of this document to provide an analysis of the systems that can be used to place a study into a hierarchy and, depending on the system, to place the study at a different "level". Available literature on $\mathrm{PH}$ prevention with mesh in the context of laparoscopic approach can be broadly categorized as those studies of an observational nature ("low quality of evidence") and those studies that have a randomized experimental design or are meta-analyses of randomized controlled trials ("high quality of evidence"). The aim of this document is to review the studies present in MEDLINE (Pubmed) related to $\mathrm{PH}$ prevention with mesh in the context of laparoscopic approach (main procedure and/ 
or mesh placement) and by stoma type (i.e., end-colostomy, end-ileostomy, and ileal conduit diversion) from the "lowest" to "highest" quality. (Search terms- "ostomy", "end-colostomy", "endileostomy", "ileal conduit diversion", "laparoscopy", "prophylaxis", "prevention", "surgical mesh", "prosthesis", "implant", "parastomal hernia"). Table 1 presents a summary of the included studies.

\section{END-COLOSTOMY}

\section{Observational Studies}

Observational studies (ObS) are clinical research designs whose goal is the observation and description of events without any intervention in their natural course. ObS represent $80 \%$ of the publications in biomedical journals, independent of the database indexing and eventual impact factor of each journal (24). Most of the studies we found on $\mathrm{PH}$ prevention with mesh in the context of laparoscopic approach were observational and relating to endcolostomy construction in an elective setting (12-19). Apart from the inherent methodologic limitations of ObS that generate bias (25), the studies we found comprise a limited number of patients (143 patients), and the results related to laparoscopic approach are indirect, because six of eight studies $(12,15-19)$ combined the open and laparoscopic approach. Regarding mesh position, the studies are heterogeneous: in three studies the mesh position is an intraperitoneal onlay (IPOM) with a gap in the middle of the mesh (Keyhole) $(12,14,18)$, in two a retromuscular position with a keyhole mesh $(13,17)$, in two an IPOM modified Sugarbaker technique $(15,19)$, and in one study the authors use their own mesh position they call SMART (16). The type of mesh used in this ObS is mostly a synthetic non-absorbable mesh (12-15, 17-19) and in only one study the prosthetic material is absorbable and of biologic origin (16). Additionally, the material architecture is heterogeneous: in three studies the authors use a prefabricated square mesh device with a central funnel-shaped cannel $(12,14$, 18 ), in two a round composite mesh with a central band protecting the bowel from erosion $(15,19)$, and in three a flat mesh $(13,16$, 17). On the other hand, in all ObS related to an end-colostomy (12-19), the follow-up was 2 years or less, and at this point, it is necessary to remember that the time elapsed since the formation of the stoma may be an important factor in relation to the onset of a $\mathrm{PH}$, since although it appears that $50 \%$ of the $\mathrm{PH}$ will be diagnosed in the first 2 years of follow-up, the risk may continue for at least 20 years (26). All ObS related to an end-colostomy had a positive conclusion in favor of the use of a prophylactic mesh in terms of safety and efficacy.

\section{Randomized Controlled Trials (RCTs)}

Probably, well-conducted RCTs are the best type of study for determining whether there is a causal relationship between intervention and effect (27). Although RCTs are the gold standard with regard to level of evidence, the extent to which their results can be extrapolated to the wider patient population (i.e., generalizability, external validity) is questionable because standardized and controlled study conditions do not adequately reflect the clinical reality. In the previous context real world evidence (i.e., registries) have been advocated as the best way to monitor the effects of a treatment or intervention long-term, as in the case of prevention with a medical device (i.e., mesh) (28). However, both types of data (i.e., registries and RCTs) should be complementary in the total product life cycle (i.e., preventive mesh) evaluation (29). To the best of our knowledge, no data derived from registries are present in the literature related to $\mathrm{PH}$ prevention with mesh in the context of laparoscopic approach. We found five RCTs regarding $\mathrm{PH}$ prevention with mesh in the context of laparoscopic approach $(4,20-23)$. Similarly to the aforementioned ObS, the RCTs found comprise a limited number of patients (212 patients) and only three studies exclusively analyze patients operated on by laparoscopic approach $(4,21,23)$. Regarding mesh position, no uniformity was followed because two used an IPOM keyhole position $(4,21)$, one a retromuscular keyhole (20), one a 3D implant around stoma (22), and one an IPOM modified Sugarbaker technique (23). Also, in all RCTs $(4,20-23)$ the follow-up was 2 years or less, and the type of mesh was heterogeneous, including biological (20) and synthetic non-absorbable meshes (4, 21-23). Furthermore, the mesh used in one RCT (23) has been withdrawn from the market (30). Regarding conclusions, two studies state that $\mathrm{PH}$ prevention using a laparoscopic approach is safe and effective $(4,23)$, in one study the mesh was clinically effective but radiologically ineffective (21), in one the conclusion was that the mesh did not significantly reduce the incidence of PH (20), and finally, one of the RCTs was an interim analysis, and no statistical analysis was performed (22).

\section{Meta-Analysis}

Alongside high-quality RCTs with a low risk of systematic error (bias), meta-analyses of these provide the highest level of evidence (9). Different meta-analyses have been published in connection with $\mathrm{PH}$ prevention with mesh. However, it is not our intention to analyze all of them. We selected only one (8) because, to the best of our knowledge, this meta-analysis is the only one that includes a trial sequential analysis (TSA), and TSA is a statistical tool recommended for inclusion in a meta-analysis (31). TSA is a methodology that combines an optimal information size (OIS) calculation for a meta-analysis with the threshold of statistical significance (statistical reliability of data), controls the risk of type I errors (false-positive results), and helps to clarify whether additional trials are needed in the topic under study. The conclusions of this meta-analysis (8) were that $\mathrm{PH}$ prevention with a permanent synthetic mesh, in a retromuscular position, when creating an end-colostomy by an open approach significantly reduces the incidence of $\mathrm{PH}$ and the risk for subsequent $\mathrm{PH}$ repair and does not increase surgical site infections. The reduction in $\mathrm{PH}$ incidence is more pronounced when only clinical follow-up is done compared with systematic CT scan follow-up. TSA shows that the OIS is reached for the primary outcome ( $\mathrm{PH}$ prevention), and additional RCTs in the previous context are not needed. More data are needed to increase precision and obtain firm evidence regarding $\mathrm{PH}$ repair reduction, the low rate of surgical site infections, and the effectiveness of laparoscopic approach. 


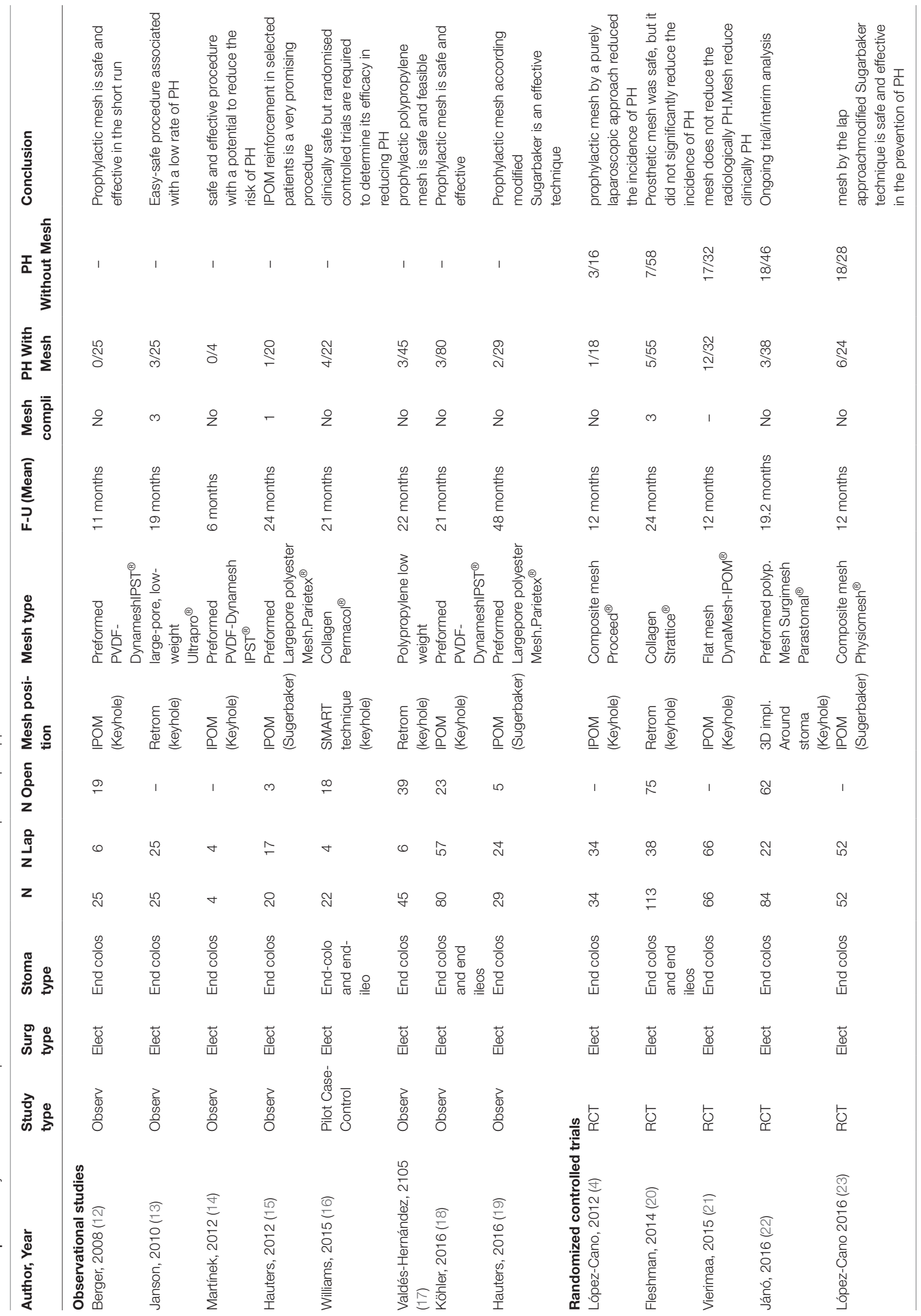




\section{END-ILEOSTOMY AND ILEAL CONDUIT DIVERSION}

Regarding end-ileostomy, only two observational studies $(16,18)$ and one RCT (20) included patients with this type of ostomy in the context of laparoscopic approach. The number of patients was very limited, and no comments can be made in relation to this type of ostomy. No studies were found about $\mathrm{PH}$ prevention with mesh in the context of laparoscopic approach in connection with an ileal conduit diversion.

\section{SUMMARY}

Based on the current data, $\mathrm{PH}$ prevention with mesh in the context of laparoscopic approach is an unresolved issue. Most research is observational with positive findings and conclusions in favor of the use of a prophylactic mesh in terms of safety and efficacy (12-19). However, the inability to attribute causation (a fundamental limitation of observational research) was rarely mentioned in different papers. A possible consequence of inadequate reporting of limitations of observational studies is that readers consider the reported associations to be causal, promoting

\section{REFERENCES}

1. Spaner SJ, Warnock GL, Gl W. A brief history of endoscopy, laparoscopy, and laparoscopic surgery. J Laparoendosc Adv Surg Tech A (1997) 7(6):369-73. doi: 10.1089/lap.1997.7.369

2. Shah NR, Craft RO, Harold KL. Parastomal hernia repair. Surg Clin North Am (2013) 93(5):1185-98. doi: 10.1016/j.suc.2013.06.011

3. Cingi A, Cakir T, Sever A, Aktan AO. Enterostomy site hernias: a clinical and computerized tomographic evaluation. Dis Colon Rectum (2006) 49(10):155963. doi: 10.1007/s10350-006-0681-4

4. López-Cano M, Lozoya-Trujillo R, Quiroga S, Sánchez JL, Vallribera F, Martí M, et al. Use of a prosthetic mesh to prevent parastomal hernia during laparoscopic abdominoperineal resection: a randomized controlled trial. Hernia (2012) 16(6):661-7. doi: 10.1007/s10029-012-0952-z

5. Carne PW, Robertson GM, Frizelle FA. Parastomal hernia. Br J Surg (2003) 90(7):784-93. doi: 10.1002/bjs.4220

6. Liu NW, Hackney JT, Gellhaus PT, Monn MF, Masterson TA, Bihrle R, et al. Incidence and risk factors of parastomal hernia in patients undergoing radical cystectomy and ileal conduit diversion. J Urol (2014) 191(5):1313-8. doi: 10.1016/j.juro.2013.11.104

7. Hansson BM, Slater NJ, van der Velden AS, Groenewoud HM, Buyne OR, de Hingh $\mathrm{IH}$, et al. Surgical techniques for parastomal hernia repair: a systematic review of the literature. Ann Surg (2012) 255(4):685-95. doi: 10.1097/ SLA.0b013e31824b44b1

8. López-Cano M, Brandsma HT, Bury K, Hansson B, Kyle-Leinhase I, Alamino JG, et al. Prophylactic mesh to prevent parastomal hernia after end colostomy: a meta-analysis and trial sequential analysis. Hernia (2017) 21(2):177-89. doi: 10.1007/s10029-016-1563-x

9. Djulbegovic B, Guyatt GH. Progress in evidence-based medicine: a quarter century on. Lancet (2017) 390(10092):415-23. doi: 10.1016/S01406736(16)31592-6

10. Atkins D, Best D, Briss PA, Eccles M, Falck-Ytter Y, Flottorp S, et al. Grading quality of evidence and strength of recommendations. BMJ (2004) 328(7454):1490. doi: 10.1136/bmj.328.7454.1490

11. Atkins D, Eccles M, Flottorp S, Guyatt GH, Henry D, Hill Set al, et al. Systems for grading the quality of evidence and the strength of recommendations I: preventive practices based on evidence of modest quality. Few research studies on $\mathrm{PH}$ prevention with mesh in the context of laparoscopic approach have been based on RCTs (4, 20-23), and this research is heterogeneous with no uniform conclusions and unable to give a general recommendation. Furthermore, to the best of our knowledge, no data derived from registries are present in the literature. Data derived from meta-analyses (8) reveal with firm evidence that $\mathrm{PH}$ prevention with a permanent synthetic mesh, in a retromuscular position, when creating an end-colostomy by an open approach significantly reduces the incidence of $\mathrm{PH}$. However, more data are needed to increase precision and obtain firm evidence regarding laparoscopic approach. In conclusion, more data are needed in the form of well-designed observational studies, RCTs, and registries on $\mathrm{PH}$ prevention with mesh in the context of laparoscopic approach (main procedure and/or mesh placement).

\section{AUTHOR CONTRIBUTIONS}

MLC designed the study, reviewed the literature, wrote the paper, and prepared the final draft. JAP reviewed the manuscript and approved the final draft. critical appraisal of existing approaches The GRADE Working Group. BMC Health Serv Res (2004) 4(1):38. doi: 10.1186/1472-6963-4-38

12. Berger D. Prevention of parastomal hernias by prophylactic use of a specially designed intraperitoneal onlay mesh (Dynamesh IPST). Hernia (2008) 12(3):243-6. doi: 10.1007/s10029-007-0318-0

13. Janson AR, Jänes A, Israelsson LA. Laparoscopic stoma formation with a prophylactic prosthetic mesh. Hernia (2010) 14(5):495-8. doi: 10.1007/ s10029-010-0673-0

14. Martínek L, Dostalík J, Gunková P, Gunka I, Mazur M. [Prevention of parastomal hernia using laparoscopic introduction of a prosthetic mesh-initial experience]. Rozhl Chir (2012) 91(4):216-8.

15. Hauters P, Cardin JL, Lepere M, Valverde A, Cossa JP, Auvray S. Prevention of parastomal hernia by intraperitoneal onlay mesh reinforcement at the time of stoma formation. Hernia (2012) 16(6):655-60. doi: 10.1007/s10029012-0947-9

16. Williams NS, Hotouras A, Bhan C, Murphy J, Chan CL. A case-controlled pilot study assessing the safety and efficacy of the Stapled Mesh stomA Reinforcement Technique (SMART) in reducing the incidence of parastomal herniation. Hernia (2015) 19(6):949-54. doi: 10.1007/s10029-015-1346-9

17. Valdés-Hernández J, Díaz Milanés JA, Capitán Morales LC, del Río La Fuente FJ, Torres Arcos C, Cañete Gómez J, et al. Prevention of parastomal hernia with a preperitoneal polypropelene mesh. Cir Esp (2015) 93(7):455-9. doi: 10.1016/j.cireng.2014.10.012

18. Köhler G, Hofmann A, Lechner M, Mayer F, Wundsam H, Emmanuel K, et al. Prevention of parastomal hernias with 3D funnel meshes in intraperitoneal onlay position by placement during initial stoma formation. Hernia (2016) 20(1):151-9. doi: 10.1007/s10029-015-1380-7

19. Hauters P, Cardin JL, Lepere M, Valverde A, Cossa JP, Auvray S, et al. Longterm assessment of parastomal hernia prevention by intra-peritoneal mesh reinforcement according to the modified Sugarbaker technique. Surg Endosc (2016) 30(12):5372-9. doi: 10.1007/s00464-016-4891-0

20. Fleshman JW, Beck DE, Hyman N, Wexner SD, Bauer J, George V, et al. A prospective, multicenter, randomized, controlled study of non-crosslinked porcine acellular dermal matrix fascial sublay for parastomal reinforcement in patients undergoing surgery for permanent abdominal wall ostomies. Dis Colon Rectum (2014) 57(5):623-31. doi: 10.1097/ DCR.0000000000000106 
21. Vierimaa M, Klintrup K, Biancari F, Victorzon M, Carpelan-Holmström M, Kössi J, et al. Prospective, randomized study on the use of a prosthetic mesh for prevention of parastomal Hernia of permanent colostomy. Dis. Colon Rectum (2015) 58(10):943-9. doi: 10.1097/DCR.0000000000000443

22. Jánó Z, Mohos E, Réti G, Kovács T, Mohay J, Berki C, et al. [Our experiences with the use of 3-dimensional meshes to prevent and to repair parastomal hernias]. Magy Seb (2016) 69(4):150-8. doi: 10.1556/1046.69.2016.4.2

23. López-Cano M, Serra-Aracils X, Mora L, Sánchez-García JL, Jiménez-Gómez LM, Martí M, et al. Preventing parastomal Hernia using a modified sugarbaker technique with composite mesh during laparoscopic abdominoperineal resection: a randomized controlled trial. Ann Surg (2016) 264(6):923-8. doi: 10.1097/SLA.0000000000001684

24. Manterola C, Otzen T, Studies O. The most commonly used designs in clinical research. Int J Morphol (2014) 32(2):634-45.

25. Wang MT, Bolland MJ, Grey A. Reporting of limitations of observational research. JAMA Intern Med (2015) 175(9):1571-2. doi: 10.1001/ jamainternmed.2015.2147

26. Londono-Schimmer EE, Leong AP, Phillips RK. Life table analysis of stomal complications following colostomy. Dis Colon Rectum (1994) 37(9):916-20. doi: 10.1007/BF02052598

27. Kabisch M, Ruckes C, Seibert-Grafe M, Blettner M. Randomized controlled trials: part 17 of a series on evaluation of scientific publications. Dtsch Arztebl Int (2011) 108(39):663-8. doi: 10.3238/arztebl.2011.0663
28. Gliklich RE, Dreyer NA, Leavy MB, editors. Registries for Evaluating Patient Outcomes: A User's Guide. 3rd ed. Rockville (MD): Agency for Healthcare Research and Quality (US) (2014).

29. Sedrakyan A, Campbell B, Merino JG, Kuntz R, Hirst A, Mcculloch P. IDEAL$D$ : a rational framework for evaluating and regulating the use of medical devices. BMJ (2016) 353:i2372. doi: 10.1136/bmj.i2372

30. Köckerling F, Simon T, Hukauf M, Hellinger A, Fortelny R, Reinpold W, et al. The importance of registries in the postmarketing surveillance of surgical meshes. Ann Surg (2017):1. doi: 10.1097/SLA.0000000000002326

31. Roberts I, Ker K, Edwards P, Beecher D, Manno D, Sydenham E. The knowledge system underpinning healthcare is not fit for purpose and must change. BMJ (2015) 350:h2463. doi: 10.1136/bmj.h2463

Conflict of Interest Statement: The authors declare that the research was conducted in the absence of any commercial or financial relationships that could be construed as a potential conflict of interest.

Copyright $\odot 2018$ López-Cano and Pereira Rodriguez. This is an open-access article distributed under the terms of the Creative Commons Attribution License (CC BY). The use, distribution or reproduction in other forums is permitted, provided the original author(s) and the copyright owner are credited and that the original publication in this journal is cited, in accordance with accepted academic practice. No use, distribution or reproduction is permitted which does not comply with these terms. 